\title{
PERCEPÇÃO DAS ENFERMEIRAS SOBRE A PRESENÇA DO ACOMPANHANTE NA INTERNAÇÃO HOSPITALAR DO IDOSO
}

\author{
Juliana Mendes ${ }^{1}$, Mariluci Alves Maftum², Maria Ribeiro Lacerda ${ }^{3}$, Maria de Fátima Mantovani ${ }^{4}$
}

RESUMO: Pesquisa qualitativa e exploratória desenvolvida no Centro de Terapia Semi-Intensiva de um Hospital Público de Ensino de Curitiba, em 2008, com o objetivo de conhecer como o enfermeiro percebe a presença do acompanhante no cuidado de enfermagem ao idoso internado. Participaram da pesquisa sete enfermeiras, e os dados foram coletados mediante entrevista semiestruturada e apresentados em categorias. Evidenciou-se, pela percepção dos sujeitos, que o acompanhante deveria permanecer com o idoso durante o período de internação por ser agente facilitador do cuidado, entretanto foram relatadas dificuldades com relação ao espaço físico para sua acomodação. O abandono foi expresso como obstáculo à continuidade do cuidado após a alta hospitalar. Concluiu-se que, para o cuidado integral ao idoso há necessidade de a equipe de enfermagem introduzir o acompanhante nos cuidados, no sentido de favorecer seu preparo e treinamento, com vistas à continuidade do cuidado ao idoso no domicílio.

PALAVRAS-CHAVE: Idoso; Família; Enfermagem.

\section{PERCEPTION OF NURSES ON THE PRESENCE OF A COMPANION TO THE HOSPITALIZED ELDERLY}

\begin{abstract}
A qualitative and exploratory study was developed at the Center for Semi-Intensive Therapy in a Public Teaching Hospital of Curitiba, in 2008, with the objective of identifying how nurses perceive the presence of a companion during nursing care to hospitalized elderly. Participants were seven nurses, and data were collected through a semistructured interview, presented in categories. The subjects' perceptions evidenced that the companion should remain with the elderly during the hospitalization period by being a facilitator of care, however difficulties were reported regarding to the physical space for their accommodation. The abandonment was expressed as a barrier to continuity of care after discharge. It was concluded that there's a need for the nursing staff to introduce the companion in care integral care, fostering their preparation and training, in order to seek the continuity of care to the elderly at home.
\end{abstract}

KEYWORDS: Elderly; Family; Nursing.

\section{PERCEPCIÓN DE LAS ENFERMERAS SOBRE LA PRESENCIA DEL ACOMPAÑANTE EN LA INTERNACIÓN HOSPITALAR DEL ANCIANO}

RESUMEN: Investigación cualitativa y exploratória desarrollada en Centro de Terapía Semintensiva de un Hospital Público de Enseñanza de Curitiba, en 2008, con el objetivo de conocer cómo el enfermero percibe la presencia del acompañante en cuidado de enfermería al anciano internado. Han participado de la investigación siete enfermeras, y los datos fueron recogidos por medio de entrevista semiestructurada y presentados en categorías. Se evidenció, por la percepción de los sujetos, que el acompañante debería permanecer con el anciano durante el periodo de internación por ser agente facilitador del cuidado, pero fueron relatadas dificultades acerca del espacio físico para su acomodación. El abandono fue expresado como obstáculo a la continuidad del cuidado pos la alta hospitalar. Se concluyó que, para el cuidado integral al anciano, hay necesidad del equipo de enfermería introducir el acompañante en los cuidados, a fin de favorecer su preparación y entrenamiento, para la continuidad del cuidado al anciano en domicilio.

PALABRAS CLAVE: Anciano; Familia; Enfermería.

${ }^{1}$ Enfermeira. Mestre em Enfermagem. Enfermeira do Hospital de Clínicas da Universidade Federal do Paraná-HC-UFPR.

${ }^{2}$ Enfermeira. Doutora em Enfermagem. Professor Adjunto do Departamento de Enfermagem da UFPR. Vice-líder do Núcleo de Estudos, Pesquisa e Extensão do Cuidado Humano de Enfermagem-NEPECHE.

${ }^{3}$ Enfermeira. Doutora em Enfermagem. Professor Adjunto do Departamento de Enfermagem-UFPR. Líder do NEPECHE. Coordenadora do Programa de Pós-Graduação em Enfermagem-UFPR.

${ }^{4}$ Enfermeira. Doutora em Enfermagem. Professor Adjunto do Departamento de Enfermagem-UFPR. Docente do Programa de PósGraduação em Enfermagem-UFPR. Membro do Grupo de Estudos Multiprofissional em Saúde do Adulto-GEMSA.

Autor correspondente:

Mariluci Alves Maftum

Universidade Federal do Paraná

R. João Clemente Tesseroli, 90 - 81520-190 - Curitiba-PR, Brasil

Recebido: 19/07/10

E-mail:maftum@ufpr.br

Aprovado: 05/09/10

Cogitare Enferm. 2010 Jul/Set; 15(3):448-53 


\section{INTRODUÇÃO}

No decorrer do processo de envelhecimento, as pessoas apresentam mudanças biopsicossociais e espirituais e, em muitos casos, podem ser acometidas por patologias que levam a internações hospitalares. Os serviços em que essas internações ocorrem incluem os Centros de Terapia Semi-Intensiva (CTSI), unidades complexas destinadas ao atendimento de pacientes graves que demandam espaço físico específico, recursos humanos especializados e instrumental tecnológico avançado ${ }^{(1-2)}$.

O idoso, ao ser inserido neste ambiente, pode apresentar sentimentos de medo, angústia, raiva, perda da privacidade, depressão, entre outros. A mudança de ambiente junto com as mudanças decorrentes da idade pode ser percebida como fator estressor para o idoso internado no CTSI, entretanto, a permanência do acompanhante durante o período de internação pode minimizar esta situação $0^{(1-2)}$.

De acordo com a Política Nacional do Idoso, todos os idosos têm direito de permanecer com acompanhante durante a internação, bem como a instituição tem o dever de proporcionar ambiente propício para a permanência do acompanhante ${ }^{(2)}$.

Os familiares desempenham papel importante durante o processo de internação do idoso, visto que será o maior responsável pelo seu cuidado após a alta hospitalar. A maneira como o familiar cuida do idoso influenciará na sua recuperação e respectivo retorno à sociedade, o mais rápido possível ${ }^{(1)}$.

A reabilitação do idoso pode variar de acordo com o cuidado ofertado pela família e, da mesma maneira, as respostas da família ao idoso podem influenciar nas suas reações. Dessa forma, deve-se levar em consideração o desafio que envolve a manutenção e reabilitação da capacidade funcional do idoso. Isso porque esse trabalho deve envolver os profissionais de saúde, idosos, familiares e/ou cuidadores, a fim de desenvolver espaços que viabilizem o envelhecimento ativo para os idosos no Brasil ${ }^{(3)}$.

Assim, o cuidado da Enfermagem deve fornecer suporte educativo ao idoso e à sua família para a continuidade do cuidado em longo prazo, que deve ser planejado a partir da hospitalização e dirigido para oferecer alternativas ao segmento, por meio do cuidado domiciliar ${ }^{(4)}$. É necessário que a enfermeira estimule o cuidado e o envolvimento de todos, incluindo o idoso e os familiares, sendo estes últimos, os partícipes mais significativos no processo de cuidar ${ }^{(5)}$. Neste sentido, ao estabelecer um plano terapêutico de alta hospitalar do idoso, pode-se contribuir na redução das complicações e agravamento dos quadros de morbidade, o que implicará prevenção de internações hospitalares ${ }^{(6)}$.

Assim, torna-se fundamental que o cuidado seja realizado de forma integral e pluralista, incluindo os familiares e os demais envolvidos no processo de viver do idoso. O cuidado deve ser baseado no princípio da integralidade, preservando a individualidade e a forma única com que cada idoso vivencia seu processo de envelhecimento ${ }^{(2,7)}$.

O objetivo desta pesquisa foi conhecer como o enfermeiro percebe a presença do acompanhante no cuidado de enfermagem ao idoso internado no CTSI.

\section{METODOLOGIA}

Pesquisa qualitativa do tipo exploratória, desenvolvida em 2008, em um CTSI de um Hospital Público de Ensino de Curitiba, Paraná; participaram da pesquisa as sete enfermeiras assistenciais que desenvolvem cuidados diretos aos pacientes internado. Os dados foram obtidos mediante entrevista semiestruturada com a questão: como você percebe a presença do acompanhante no cuidado de enfermagem ao idoso internado no CTSI?

O projeto de pesquisa foi aprovado pelo Comitê de Ética do referido hospital sob o protocolo de n. CAAE 0204.0.208.000-07, Registro CEP 1523.188/2007-09. Foram respeitados os preceitos éticos, segundo a Resolução n. 196/96 do Ministério da Saúde, por meio da assinatura do Termo de Consentimento Livre e Esclarecido pelas participantes do estudo ${ }^{(8)}$.

Os dados provenientes das entrevistas foram analisados de acordo com a proposta de análise temática de Minayo, que inclui as fases de ordenação dos dados, classificação dos dados e análise final dos temas emergentes ${ }^{(9)}$.

Na fase de Ordenação dos dados, foram reunidas as entrevistas, procedendo-se à sua transcrição, à leitura do material e sendo organizados os relatos que se assemelhavam. Na fase de Classificação dos dados, foi feita uma leitura exaustiva das entrevistas, permitindo apreender a relevância entre as falas. A fase de Análise final destinou-se à organização das categorias temáticas dos dados coletados.

\section{RESULTADOS E DISCUSSÕES}

Os dados das entrevistas com as enfermeiras 
participantes deste estudo resultaram nas seguintes categorias: o acompanhante no tratamento do idoso na percepção das enfermeiras; o acompanhante como facilitador do cuidado ao idoso; e o preparo da família para a continuidade do cuidado ao idoso no domicílio.

\section{O acompanhante no tratamento do idoso na per- cepção das enfermeiras}

Os sujeitos relataram que, em princípio, tinham resistência em que o acompanhante permanecesse no CTSI por temer que ele interferisse de modo negativo no trabalho da Enfermagem. Apresentaram a falta de espaço físico como uma das dificuldades em aceitar a permanência do acompanhante com o idoso, mas, apesar disso, forneceram esclarecimentos de que é um direito garantido a eles.

Eu tinha resistência de pessoas idosas ficarem com acompanhantes, pois pensava que atrapalhavam a assistência de enfermagem. Quando interna um paciente, digo: aqui neste setor não fica acompanhante, mas pela idade do seu familiar, se você quiser é um direito e você pode ficar. (Enf. 1)

Teria que ser uma estrutura física que ofamiliar pudesse acompanhar, para que ele não se sentisse perdido, muito fora do lar, da casa, do seu aconchego. O idoso em si não é tão difícil de atender. Às vezes, é mais difícil atender à família que o acompanha, porque ela não entende os nossos procedimentos [...]. Fica difícil atender a vários idosos ao mesmo tempo, porque eles têm direito a ter acompanhante [...]. (Enf. 3)

As dificuldades da permanência do acompanhante/familiar do idoso são pontuais e envolvem, principalmente, a inadequação da infraestrutura ${ }^{(10)}$, que é incapaz de proporcionar conforto e acompanhamento do paciente, conforme foi relatado pela participante Enf. 3.

A Portaria do Ministério da Saúde n. 280/99 torna obrigatória, nos hospitais públicos contratados ou conveniados com o Sistema Único de Saúde (SUS), a permanência do acompanhante hospitalar para pacientes maiores de 60 anos de idade. Esta portaria estabelece que o hospital receba do SUS diária de acompanhante, quando devidamente formalizada pela Autorização de Internação Hospitalar ${ }^{(11)}$. A oportunidade que a Lei oferece ao prever a permanência do acompanhante ao idoso hospitalizado merece ser aproveitada no sentido de favorecer sua participação ativa no cuidado ao cliente.

No entanto, é possível identificar que, no dia a dia dos serviços de saúde, tal participação, quando ocorre, na maioria das vezes, é passiva, pois tanto os clientes como seus acompanhantes obedecem às prescrições dos profissionais de forma mecânica, sem propriamente serem preparados para entender os porquês dos cuidados ${ }^{(12)}$.

Uma enfermeira relatou que se sente frustrada quando ocorre abandono do idoso pelo familiar no momento da alta, pois verifica que todos os esforços dispensados durante o período de internação acabam se perdendo devido à falta de participação do familiar no cuidado, afirmando que este é um dos motivos para a depressão do idoso e, consequentemente, de sua morte:

Às vezes, ficamos de mãos atadas, porque a família não o quer. Está de alta e não vem buscá-lo. É o maior sentimento que a gente tem com este idoso de alta, e a família não quer levá-lo. Ev você investiu todo o tempo, toda terapêutica para deixar ele bem, e a familia não quer recebê-lo. Se ele fica sabendo disso, ou percebe, ele fica muito triste. Tem paciente que chega à casa e vai a óbito. E todo o trabalho foi em vão, porque a família não deu continuidade. Ele percebeu que era um intruso naquela convivência, acaba se deprimindo e indo embora. (Enf. 3)

Diversos são os fatores que influenciam na presença ou ausência da família no momento da internação, entre eles os econômicos, sociais e emocionais. Há que se pensar nestas questões, inerentes ao âmbito familiar, visto que a família é considerada a principal responsável pelo cuidado ao idoso ${ }^{(7)}$.

Em relação ao abandono do idoso, convém destacar o cuidado que se apresenta de modo inadequado, ineficiente ou mesmo inexistente, observado em situações nas quais os membros da família não estão dispostos, estão despreparados ou sobrecarregados por esta responsabilidade. Também, pelo fato de os padrões familiares estarem mudando em face das transformações sociais, econômicas e demográficas, mudam-se os valores culturais em relação ao idoso e ao cuidado familiar a este ${ }^{(7)}$.

Em estudo realizado na Suécia( ${ }^{(13)}$, verificouse que há mudança na estrutura familiar. Esta nova família é composta do marido, esposa e, na maioria das vezes, não há filhos; dessa forma, o número de 
pessoas que vivem sozinhas está em crescimento. Os idosos normalmente presenciam o distanciamento de seus parentes, principalmente no internamento hospitalar. Naquele estudo, os autores relatam que os pacientes que não recebem visitas são mais vulneráveis e possuem poucas chances de sobrevivência e, na visão do paciente, o familiar muitas vezes é mais importante do que o próprio profissional da saúde.

\section{O acompanhante como facilitador do cuidado ao idoso}

Nos relatos a seguir, as enfermeiras ressaltaram a importância da família no cuidado ao idoso. Mencionaram que, pelo fato de a família conhecer melhor as preferências e o jeito de ser e se comunicar do idoso, ela contribui no desenvolvimento do cuidado, principalmente à noite, quando ele tem mais dificuldade em entender por que está longe de seu lar, e isso lhe causa insegurança:

[...] teria que ser diferente a participação da família [...] principalmente à noite, muitas pessoas idosas que estão fora do seu local [lar] e não entendem por que têm que ficar no hospital. Se houvesse alguém da familia que participasse do cuidado, ficasse com eles, seria melhor a permanência deles no setor. Às vezes, que a gente ficou com familiar à noite com o idoso percebi que ele se sente mais seguro, é como se esse familiar fizesse uma tradução para a gente. Ele está acostumado [...] ele dorme assim mesmo, de lado, diferente e eu fui colocar ele deitado daquele lado. O familiar está mais acostumado em casa e faz como se fosse a tradução dos costumes e da forma como ele vive fora daqui. (Enf. 2)

[...] o paciente que tem um acompanhante junto [...] muitas vezes prefere que a família o alimente porque é o que fazem em casa, então eu oriento e estimulo a familia para que ela possa fazer este cuidado para o doente. (Enf. 5)

A permanência de acompanhantes com o paciente de Unidades de Terapia Intensiva (UTI) pode ser considerada uma inovação. Em 2007, foi desenvolvido um estudo ${ }^{(14)} \mathrm{em}$ uma instituição que possuía leitos de UTI, sobre os limites e as possibilidades da permanência de acompanhantes na unidade, tendo respondido ao questionário 42 funcionários e 20 acompanhantes. Os resultados mostraram que os acompanhantes se sujeitam às normas estabelecidas como a condição de manter sua permanência. Mesmo reconhecendo os benefícios que o acompanhante traz para o paciente, naquele estudo os funcionários relataram algumas restrições, dentre as quais, seu próprio despreparo em lidar com a família.

No estudo realizado em UTI de adultos, de um Hospital Universitário de Santa Catarina, verificou-se que os enfermeiros valorizam a participação dos familiares na recuperação dos pacientes, pois acreditam que o contato com o familiar ajuda no tratamento. Naquela pesquisa, os enfermeiros eram flexíveis em relação a algumas rotinas da unidade como, por exemplo, o horário de visita ${ }^{(15)}$.

Na Unidade de Terapia Intensiva Geral da Suécia, os enfermeiros também disponibilizam horário flexível para as visitas, dependendo do estado de saúde do paciente, visitas às crianças são liberadas sem restrições. Naquela unidade, verificou-se que o familiar é percebido como de suma importância para a recuperação do paciente idoso, por isso houve flexibilidade do horário de visitas, de uma vez ao dia para duas vezes. Estes horários foram deixados próximos às refeições para que o familiar pudesse participar dos cuidados básicos, e essa mudança foi bem aceita por todos da equipe e familiares ${ }^{(13)}$.

\section{O preparo da família para a continuidade do cuidado ao idoso no domicílio}

As enfermeiras externaram a necessidade de o familiar ser orientado para a continuidade ao cuidado do idoso em seu domicílio. Enfocaram a importância de a família ser inserida no contexto em que vive o idoso, para se tornar uma aliada e participante no seu tratamento e respectiva recuperação:

\section{Trabalhar com idoso não só demanda o trabalho com ele, mas com a família também. (Enf. 3)}

Tem que envolver família, fazer grupos com os familiares de pessoa idosa, até porque muitos pacientes vão de alta e precisam de um cuidado pós a alta. [...] uma acomodação melhor para o idoso e os demais acompanhantes, uma conversa melhor com a familia que a enfermagem perde muito isso. A familia entra e a enfermagem sai de cena muitas vezes e não conversa com a família, não interage com ela. (Enf. 6)

Os relatos anteriores enfatizam a importância 
do cuidado de enfermagem com a família, dando-lhe a oportunidade de expor suas dúvidas, medos e sentimentos, garantindo-lhe o apoio e a participação no tratamento do paciente. Os profissionais da saúde, quando capacitam e integram o idoso e a família no processo de cuidar, proporcionam ao idoso uma participação ativa de seus cuidados e tratamento, contribuindo para que ele aceite melhor o internamento, e ao acompanhante a segurança durante a hospitalização ${ }^{(16)}$.

O retorno do idoso ao domicílio exige disponibilidade de espaço, pessoa para prestar o cuidado e recursos econômicos, o que pode trazer desestruturação familiar. Para tanto, faz-se necessário que o enfermeiro observe e atue junto à família para que possa identificar as alterações e desenvolver o plano de cuidado de enfermagem ${ }^{(17)}$. Destarte, a demanda que o cuidado domiciliar exige do cuidador familiar, além de disposição e boa vontade, habilidades e conhecimentos com os quais não está habituado e nem preparado ${ }^{(18)}$.

$\mathrm{O}$ idoso que participa ativamente de seus cuidados e tratamento aceita melhor sua internação, e o familiar cuidador sente-se mais seguro e preparado para a alta hospitalar. É evidente a importância que a família apresenta no tratamento do idoso, pois após a alta hospitalar é ela a principal responsável pela reabilitação dele pois, muitas vezes, o paciente pode estar mais fragilizado do que estava na ocasião de sua internação. Percebe-se que, quando a família está envolvida no plano de tratamento, há maior vigilância no cuidado ao idoso ${ }^{(4)}$.

Os profissionais de saúde necessitam compreender a família como aliada da equipe, pois ela pode representar um recurso pelo qual "o paciente pode reafirmar e, muitas vezes, recuperar sua importância no tratamento, de forma a investir nas suas possibilidades de recuperação". Portanto, as famílias devem ser apoiadas, se sentirem úteis e participativas no tratamento do paciente ${ }^{(19)}$.

\section{CONCLUSÃo}

O familiar é fundamental no tratamento e recuperação do idoso, principalmente quando trabalha em conjunto com a equipe de saúde. As instituições estão em busca da adequação do ambiente para poder atender à crescente população idosa e a seus acompanhantes familiares, fato que preocupou as enfermeiras deste estudo, que consideraram o acompanhante importante para a recuperação dos idosos.

$\mathrm{O}$ abandono do idoso que, por vezes, ocorre no
CTSI, preocupa as enfermeiras, visto que são investidos atenção e cuidado na sua recuperação e, no momento da alta, ele não pode retornar ou sua volta é postergada.

O cuidador do idoso é, na maioria das vezes, o familiar e, se este não tiver bom relacionamento, condições socioeconômicas e estrutura familiar para receber o idoso, ele não conseguirá prestar cuidado adequado e, consequentemente, a recuperação do idoso será prejudicada.

Portanto, a educação em saúde para os familiares é relevante e necessita ser realizada em busca do cuidado domiciliar que possa dar continuidade ao tratamento que foi estabelecido durante a hospitalização.

Constitui desafio para a Enfermagem prestar cuidado ao idoso de modo que ele possa retornar às suas atividades com o máximo de independência possível. O presente estudo vem corroborar a importância do familiar em conjunto com a equipe de saúde no processo de internação e cuidado do idoso. Assim, espera-se que o estudo contribua para novas pesquisas a respeito do tema.

\section{REFERÊNCIAS}

1. Ciampone JT, Gonçalves LA, Maia FOM, Padilha KG. Necessidades de cuidados de enfermagem e intervenções terapêuticas em unidade de terapia intensiva: estudo comparativo entre pacientes idosos e não idosos. Acta Paul Enferm. 20061;19(1):28-35.

2. Mendes J, Maftum MA, Lacerda MR, Mantovani MF, Rodrigues RAP. Nursing care to elderly in the Intensive Care Unit: qualitative exploratory research. Online Braz J Nurs [Internet]. 2009;8(2) [acesso em 27 abr 2010]. Disponível: http://tiny.cc/8h9h9

3. Caldas CP, Saldanha AL, organizadores. Saúde do idoso: A arte de cuidar. $2^{\mathrm{a}}$ ed. Rio de Janeiro: Interciência; 2004.

4. Rodrigues RAP, Casagrande LDR. Atividade educativa com as idosas que tiveram queda e seus cuidadores: atuação da enfermeira geriátrica em domicílio. Acta Paul Enferm. 1996;9(1):80-91

5. Gonçalves LHT, Alvarez AM. A enfermagem gerontogeriátrica: perspectivas e desafios. Rev Bras Ciências Envelhec Humano. 2004;1(1):57-68.

6. Figueiredo MLFÇ, Luz MHBA, Britto CMS, Sousa SNS, Silva DRS. Diagnósticos de enfermagem do idoso acamado no domicílio. Rev Bras Enferm. 2008;6(4):464-9. 
7. Caldas CP. Contribuindo para construção da rede de cuidados: trabalhando com a família do idoso portador de síndrome demencial. [Internet] 2002;8(4). [acesso em 10 nov 2009]. Disponível: http://tiny.cc/h5zp2

8. Ministério da Saúde (BR). Conselho Nacional de Saúde. Diretrizes e normas regulamentadoras de pesquisa em seres humanos. Resolução n.196, de 10 de outubro de 1996. Brasília; 1996.

9. Minayo, MCS. O desafio do conhecimento: pesquisa qualitativa em saúde. $8^{\mathrm{a}}$ ed. São Paulo: Hucitec; 2004.

10. Nascimento AZ, Ribeiro G, Bernardino E, Oliveira SE. Limites e possibilidades da permanência de familiares em unidade de terapia intensiva. Cogitare Enferm. 2007;12(4):446-51.

11. Ministério da Saúde (BR). Portaria n. 1.395 de 10 de dezembro de 1999. Aprovação da Política Nacional do Idoso. Diário Oficial da União [Internet] 13 dez 1999 [acesso 24 jul 2008]. Disponível: http://tiny.cc/oune4

12. Teixeira MLO, Ferreira MA. Uma tecnologia de processo aplicada ao acompanhante do idoso hospitalizado para sua inclusão participativa nos cuidados diários. Texto Contexto Enferm. 2009;18(3):409-17

13. Ericksson T, Bergbom I. Visits to intensive care unit patients - frequency, duration and impact on outcome. British Association of Critical Care Nurses. Nurs Crit Care. 2007;12(1):58-79.

14. Luz CF Compreendendo as restrições dos técnicos de enfermagem sobre a permanência de acompanhantes em unidade de terapia intensiva aberta. Texto Contexto Enferm. 2009;18(2):306-12

15. Pinho LB, Santos SMA. Dialética do cuidado humanizado na UTI: contradições entre o discurso e a prática profissional do enfermeiro. Rev Esc Enferm USP. 2008;42(1):66-72.

16. Schier J, Gonçalves LHT, Lima MGO. Programa de acompanhante hospitalar para paciente geriátrico. Rev Gaúcha Enferm. 2008;24(1):61-8.

17. Marques S, Rodrigues RAP, Kusumota L. O idoso após acidente vascular cerebral: alterações no relacionamento familiar. Rev Latino-Am Enfermagem. 2006;14(03):146-9.

18. Lacerda MR, Oliniski SR. O familiar cuidador e a enfermeira: desenvolvendo interações no contexto familiar. Acta Sci. Health Sci. 2004;(1):239-48.
19. Bolela F, Jericó MC. Unidades de terapia intensiva: considerações da literatura acerca das dificuldades e estratégias para sua humanização. Esc Anna Nery. 2007;10(2):301-8. 